\title{
Hypotensive Reaction after Propanidid and Atropine
}

SIR,-Dr. B. Kay's letter about a hypotensive reaction after propanidid and atropine (16 August, p. 413) would at first sight appear to describe an extreme form of the exanthematous rash commonly seen in children after atropine. In both the cases quoted, atropine was given immediately prior to the induction with propanidid, and this may suggest that the reaction was, at least partly, due to the atropine and not propanidid. However, atropine is not an essential prerequisite for this type of reaction. In a recent case $^{1}$ the circumstances were very similar to those described by Dr. Kay, but atropine was not given at any time. The reaction was almost identical, with two notable exceptions: it began with sudden severe abdominal pain, and progressed to clinical cardiac arrest.

The literature reveals only four other cases of such severe reaction to propanidid, and at least one of these did not receive atropine. ${ }^{2}$ In the more recent cases, one by Desai," the two reported by Kay, and one of my own, there is a striking similarity in the circumstances. All were sick children who required operative evacuation of collections of pus. The fact that identical reactions can occur when propanidid is given alone makes it highly unlikely that atropine is the agent responsible. Sensitivity tests with propanidid have so far failed to demonstrate any hypersensitivity or allergic phenomena, but thi does not rule out the possibility of an allergic mechanism being the cause.

It is interesting to note that five of the eight cases so far observed had received propanidid some two to three weeks previously with no untoward effect, and also that two of these cases did not receive atropine.-I am, etc.,

\footnotetext{
Royal Infirmary,
Derby.

1965, 9., Acta Anaesthesiologica

Radnay, P. A., Acta Anaesthesiologica Scandinavica, 1965, 9, Suppl. No. 17, p. 80.

Desai, $G$, personal communicato.

Johns, G., in press.
}

GwYN JoHNs.

\section{Drug Seeker}

SIR,-As a house physician I have recently come into contact with a patient seeking drugs. As this patient has certain characteristics which make him easily recognizable, I feel it would be useful to give an account of him for the benefit of other doctors.

The patient consistently gives his name as Michael Lannon, born on 10 June 1931. He is blind, with artificial eyes, and states that this resulted from an injury to the right eye after an accident seven years ago. $\mathrm{He}$ is exceedingly acute of hearing, and is able to distinguish common tablets by touch. $\mathrm{He}$ says that he has just finished training as a physiotherapist.

The presenting symptom on admission was severe chest pain radiating to the left arm, not relieved by trinitrite tablets. This was also his complaint when admitted to Mount Vernon Hospital one month previously. It became increasingly apparent that his demands for morphine were excessive, and he said he felt very strongly that no one believed that he had pain. This was part of a general impression he tried to create that he had had a very hard life and that he deserved great sympathy.

Clinical examination was normal, but the E.C.G. showed evidence of ischaemic changes: inverted and flat $T$ waves in V3-6, unchanged since his admission to Mount Vernon.

I hope this will assist anyone else who has contact with this man.-I am, etc.,

M. E. Gill.

\section{Mildmay Mission Hospital. London E.2.}

\section{Potassium Supplements}

SIR,-With reference to the recent articles and correspondence on potassium supplements, there can be little doubt about your views on potassium supplements-particularly the slow-release type. However, the important point, in my opinion and possibly that of some of your readers, is the one that "resin-based tablets may pass through the gut unchanged" expressed by your author in the "Today's Drugs" article (17 May, p. 431), which mistakenly referred to " resinbased tablets" instead of "wax-based tablets."

Despite your subsequent footnote (12 July, p. 118), stating simply that the term " resinbased" was inaccurate, without indicating the correct term intended by the author, and your latest statement of editorial opinion (23 August, p. 457), it is doubtful whether your readers have really had an opportunity to realize or consider the significance of the author's intended statement.

If the author's original viewpoint has not now changed I think it would help to clarify the situation if his intended statement were now correctly published, when you as Editor, and other practising physicians, and perhaps Messrs. Ciba could quite properly discuss and possibly counter any evidence the author might produce to support his statement.-I am, etc.

\section{Hove, Sussex.}

R. D. WISHART, Cox-Continental Ltd.

*** The author of our "Today's Drugs" article writes: "I must admit to using 'resin' imprecisely to refer to inert-base tablets. Of the available such tablets Slow-K is probably the best, and it is reassuring to know that the potassium it contains is freely absorbed (12 July, p. 118) despite the occasional appearance of tablet 'ghosts' in the faeces. Not all patients like the tablets, however, and only long-term studies will prove their complete safety in respect of gastrointestinal irritation. I have used varnished potassium chloride tablets for many years without ill-effect, but it would seem on general grounds safer to use some form of slow-release preparation.

"The real bugbear of potassium therapy in the treatment of hypertension is that the preparation, whatever it may be, has to be continued for the patient's life-span, which with modern treatment may be 20 years or more. It is for this reason that it seems best to manage without a formal potassium supplement, provided that the patient can keep his dietary potassium sufficiently high. Long- term potassium therapy needs to be acceptable to the patient as well as safe. I have been impressed by the good patient acceptance of the various effervescent forms of potassium chloride, but this may be just the attraction of novelty, and in long-term use it may well turn out that a preparation such as Slow-K is the best drug."-ED., B.M.f

\section{Hyperaldosteronism}

SIR,-Your leading article entitled " Management of Primary and Secondary Hyperaldosteronism" (23 August, p. 427) overlooked an important distinction between the high dosage of spironolactone employed diagnostically in the hypertensive patients described by Spark and Melby ${ }^{1}$ and the lower dosage employed therapeutically by Cranston and Juel-Jensen ${ }^{2}$ and Winer et al. ${ }^{3}$ This may give the erroneous impression that the sideeffects observed at high dosage occur frequently at the much lower dosages employed in the management of essential hypertension.

Spark and Melby $^{1}$ administered $400 \mathrm{mg}$. of spironolactone per day primarily in the context of a diagnostic test rather than for therapeutic purposes. Your leading article barely touched upon the main point of their publication, which was that the blood pressure response to high dosage spironolactone therapy for about four weeks is useful in distinguishing primary from secondary aldosteronism in hypertensive patients with overproduction of aldosterone, and accurately predicts their response to adrenal surgery.

Though surgery is the treatment of choice in most patients with primary aldosteronism, spironolactone can be usefully employed in their preoperative management and preparation, ${ }^{-\infty}$ and can be used in the long-term management of those unable or unwilling to undergo operation. Spark and Melby mention several patients who were managed in this way for up to six years. The dosages needed for long-term management are not always as high as those employed diagnostically, which are doubtless intended to cater for the more extreme states of aldosteronism which may be encountered. Satisfactory blood pressure control can be obtained with about $200 \mathrm{mg}$. of spironolactone per day in some cases, ${ }^{7}$ and its side-effects do not invariably preclude its long-term use.-I am, etc.,

\section{J. TIDD,}

High Wycombe G. D. Searle and Cont,

\section{ReFERENCES}

Spark, R. F., and Melby, J. C., Ansals of Internal Meddicine, 1968, 69, 685., An Lancet, 1962, 1, 116

Winer, B. M., Lubbe, W. F., and Colson, T. fournal of the American Medical Association

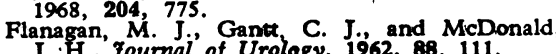
J. H., foumal of Urology, 1962, 88, 111 . B. Melby, J. C., Phe Practitioner, 1968, 200, 519. Internal Medicine, 1967, 120, T3̈.

** Though both Cranston and JuelJensen and Winer, Lubbe, and Colton have found that a slight fall in blood pressure may be produced by spironolactone, there appeared no clear advantage over diuretics and potassium supplements, which are 
cheaper. As should appear clear from the text, the leading article relates the experience of these authors with the observations of Spark and Melby on blood pressure, not on side-effects. The side-effects provide the contraindication to the use of spironolactone as a definitive long-term treatment for primary hyperaldosteronism.-ED., B.M.f.

\section{Poultry Mite Infestation}

SIR,-Pigeons are known to be associated with such conditions as aspergillosis and pigeon fanciers' lung. We wish to report an additional health hazard in which they figure.

Several patients on one ward of this hospital developed an itching, raised erythematous rash of the trunk and limbs. Numerous tiny insects were discovered on their bodies and in their bedclothes, and were subsequently identified by the Natural History branch of the British Museum as Dermanyssus gallinae (De Geer), commonly known as the red mite of poultry. It is said to be the commonest blood-sucking mite of domestic and wild birds in the British Isles. Usually, as in the present instance, human infestation can be traced to abandoned nests and roosts in the upper parts of buildings, usually old ones.

The rash subsided quickly after the patients, clothing, and bedclothes, etc., were dealt with professionally with an organophosphorus preparation.-We are, etc.,

$$
\begin{array}{cc}
\text { King's College Hospital } & \text { E. (FrEEMAN. } \\
\begin{array}{c}
\text { Geriatric Unit, } \\
\text { St. Francis's Hospital, } \\
\text { London S.E.22. }
\end{array} & \text { M. S.) KATARIA. }
\end{array}
$$

\section{Hypovitaminosis $\mathbf{B}_{12}$ in Psychiatric Patients}

SIR,-The article by Dr. F. Murphy and others (6 September, p. 559) is very misleading in its conclusions and summary from a practical point of view. The screening of the 1,004 consecutive admissions in the $50+$ age group may have led to the finding of only two cases of pernicious anaemia, but hypovitaminosis $\mathrm{B}_{12}$ was present in 34 an incidence of $3.4 \%$. Surely this was the whole point of the exercise-they had primarily psychiatric symptoms, not haematological ones. The authors seem to have forgotten that low vitamin $B_{12}$ levels can produce damage to neurones in subacute combined degeneration of the spinal cord in the absence of haematological change, and equally can do so with neurones concerned with the psyche.

If screening had been carried out routinely as suggested in an original article by $\mathrm{me}^{1}$ on an even more likely "at risk" but restricted group-females of $65+$ presenting with depression-then the percentage of positive findings might have reached something like $10 \%$. What would be important to know is the answer to the question, "How many of the patients were treated with vitamin $\mathrm{B}_{12}$ drugs by those doctors who were responsible for their total care in hospital ? "-I am, etc.,

$$
\begin{aligned}
& \text { St. Luke's Hospital, } \\
& \text { Armagh. }
\end{aligned}
$$

W. A. G. Maccallum.

Armagh.

REFERENCB

Marc Callum, W. A. G., fournal of the Irish
Mfedical Association, 1965, 57, 187.

\section{G.M.C.'s Annual Levy}

SIR,-The purpose of the General Medical Council, as I see it, is to protect the public from the activities of untrained, incompetent, or errant doctors. It is a statutory body, responsible to the public, and must be paid for by the public.

It seems quite wrong in principle to expect

doctors to contribute directly to the upkeep of such a body. As a taxpayer and potential patient I naturally and willingly expect to pay for it. As a doctor, no.-I am, etc.,

Tiverton, Devon.

J. W. Maltby.

\section{Career Prospects in Rheumatology}

SIR,-Although staffing and prospects in the N.H.S. are periodically tabulated by the Department of Health in useful attempts at guidance (Supplement, 23 August, p. 103), there is of ten considerable difficulty in obtaining facts. For example, the investigation into prospects in cardiology recently reported by Sir Max Rosenheim and his colleagues ( 26 July, p. 237) arose from the fact that the true number of consultant cardiologists in the country is not known.

The situation is equally difficult in the field of rheumatic diseases, the borders of which are not clearly defined. As far as hospital practice is concerned the care of these patients may be undertaken by general physicians, general physicians with an interest in the field, rheumatologists, or specialists in physical medicine.

I was recently requested by the education subcommittee of the Arthritis and Rheu- matism Council to prepare a report on the career structure in rheumatology. Questionaries were sent to consultant clinical members of the Heberden Society, to consultant members of the British Association of Physical Medicine, and to other physicians subsequently named by specialists from the within their region. Participants were asked to classify themselves into one of four categories: A, rheumatologist ; B, general physician with interest in rheumatology ; C, physician in physical medicine; and, $\mathrm{D}$, physician in physical medicine and rheumatology. Further details were requested about their work, junior staff, and new or unfilled posts.

One hundred and sixty-three questionaries were posted and 159 were returned completed. Participants placed themselves in the four categories as follows: A, 21; B, 28; first two categories as practising in the field
$C, 32$; and $D, 78$. There were 28 senior registrars planning a career in rheumatic diseases in this country (20 of them in categories C and D). There will be 25 consultant retire-w ments in all categories before 1975; there appear to be plans for 18 new posts; and के currently unfilled posts were named. The information obtained indicates a shortage of trainees, with a danger of consultant posts, $\overrightarrow{\vec{F}}$ at least in categories $\mathrm{A}, \mathrm{C}$, and $\mathrm{D}$, remaining? unfilled, or, because of lack of competition being filled by unsuitable candidates. The situation may be having a deleterious effects on the practice of rheumatology, but, of course, indicates good prospects for youngo men and women entering the field.

The full report was submitted to the Arthritis and Rheumatism Council earlier this year and is to be published in thew November issue of the Annals of the Rheus matic Diseases.-I am, etc.,

\section{J. T. ScotT, \\ Deputy Honorary Medical Secretar o Arthritis and Rheumatism \\ Charing Cross Hospital,
London W.C.2. \\ Care of Aged Doctors}

SIR,-It would appear that the best way of tackling the problems raised by Dr. Ke Hazell (16 August, p. 412) and Dr. J. P@ Crawford (6 September, p. 598) would be on a local basis.

Information concerning aged doctors an their dependants is likely to be obtainable from the local division of the B.M.A. or the local branch of the ladies' guild of the Royag Medical Benevolent Fund, and those are the bodies best placed to organize help. Thif would mean that the problem would be put not only on a local basis but also on a per sonal one, involving those with a direct knowledge of persons requiring help. Doctors that area could then have a personal respons sibility for the continuing care of these age doctors and their dependants.

I feel that many doctors and their families would be spurred to greater efforts regardin charitable appeals for their unfortunate col leagues if they were personally concerne with their care.-I am, etc.,

Ilford, Essex.

T. C. MAYER.

\section{Cats and Dogs}

SIR,-In reply to Dr. J. Burkinshaw comment on the etymology of Toxocara cati (13 September, p. 657) I am unable to controt the pedantic urge to point out that "catus $\frac{\mathrm{g}}{\mathrm{Q}}$ is a late Roman word for the cat (" cattus may have been used even earlier). Th evidence for the use of "catus" seems to derive mainly from writings attributed to the lower strata of Roman society, who, being probably more familiar with $T$. cati that those in a more felix position, must allowed priority.-I am, etc.,

Commonwealth Bureau of

P. S. GoOCH. 